\title{
AutiTEACCH : Mobile-based Learning in a Structured Teaching Approach for Autistic Children Caregivers
}

\author{
Ahmad Sofian Shminan \\ Faculty of Cognitive Sciences and \\ Human Development \\ Universiti Malaysia Sarawak \\ 94300 Kota Samarahan, Malaysia \\ sasofian@unimas.my
}

\author{
Lee Jun Choi \\ Faculty of Cognitive Sciences and \\ Human Development \\ Universiti Malaysia Sarawak \\ 94300 Kota Samarahan, Malaysia \\ cljun@unimas.my
}

\author{
Sabariah Sharif \\ School of Education and Social \\ Development \\ Universiti Malaysia Sabah, 88400 \\ Kota Kinabalu, Sabah, Malaysia \\ sabariah@ums.edu.my
}

\begin{abstract}
Autism Spectrum Disorder (ASD) is a neurodevelopmental disorder causing abnormality in one's social, communication and behavior. Early intervention will increase the possibility of an autistic child to have a better future. The Treatment and Education of Autistic and Communication related handicapped Children (TEACCH), is an intervention program that serves as an emerging practice for autism. The ratio of experts to ASD children is also way below par. The research aim is to establish an innovative solution by developing a mobile based learning application on TEACCH program for ASD children's caregivers. AutiTEACCH development advocates the inclusiveness of education for autistic children by providing an effective mobile learning platform for the caregivers. It aims to help reduce the cost of sending ASD children to behavior therapists, and caregivers can learn more about communication intervention and practice it themselves. AutiTEACCH has a content structure comprising of the introduction, initial preparation, strategies, and activities. ADDIE, an Instructional System Design (ISD) model is applied as the methodology with the help of the Framework for the Rational Analysis of Mobile Education (FRAME) model to construct ideal content and achieve the development goals. The contents that have been assessed by experts and caregivers' motivation in using the mobile application have been analyzed. The usefulness of the application is amply demonstrated via its many positive effects on target users. Future works may also be integrated with interesting interface designs, multilingual platforms, and the combination of other approaches in the mobile application as a centralized mobile learning.
\end{abstract}

\section{Keywords-Autism, caregivers, TEACCH, mobile learning}

\section{INTRODUCTION}

Autism Spectrum Disorder (ASD) is a term that is described by listing problems persistent in social communication and social interaction in different settings, a show of repetitive behaviours and the unwillingness to change the daily schedules [1] [2]. The symptoms usually begin in early childhood as early as the first two years of life and they cause the individuals to need assistance in their daily lives [3]. Caregivers, or specifically parents and guardians, are individuals who are involved in taking care of autistic children. These caregivers are often faced with challenges in terms of financial, psychological, and emotional aspects as they raise and take care of these children, especially to caregivers who have to send their autistic children to the autism centre [4]. They may also experience depressive mood and symptoms due to these challenges. According to Chu et al. [5], raising a child who is autistic can be overwhelming to parents and families. In other article stated that all parents interviewed expressed feelings of being overwhelmed by the intensity of caring for their child, and that mostly the burden of care tended to fall on the mothers [6]. The fear of their children wandering off unattended, or inadvertently harming themselves or other people generally caused them to suffer from high levels of anxiety. On top of caring for their child, caregivers found that even daily routines and activities were very difficult to carry out, and due to this, they struggled to find time for themselves and their other children. Mothers of autistic children expressed that the lack of necessary therapies gave parents no choice but to seek for the assistance of private therapists, which was "getting more expensive" and which caused significant financial problems because of the exorbitant costs of private therapies [7]. A child with ASD tends to have some difficulties in some areas such as social interaction, communication and behaviour [8]. Although some children have some sort of difficulties in these areas, not all children are the same so each child might have a different pattern of difficulties [9].

It is reported by Estes et al. [10] that early intervention during the ages of 0 to 6 can reduce its impact and improve the child's development. Some examples of intervention approaches for ASD children are Applied Behaviour Analysis (ABA) [11], Discrete Trial Training (DTT) [12], Picture Exchange Communication System (PECS) [13] [14] and Treatment and Education of Autistic and Communication related handicapped Children (TEACCH) [15] [16]. The TEACCH intervention program is believed to be an emerging practice for autism. TEACCH is called "Structured Teaching" that emphasizes unique learning needs of ASD people for instance, individuals with strengths in the visual information processing and problems with social communication, attention and executive function. There are a few related studies regarding the development of mobile applications for autism intervention approaches such as AutiSay [17], BIUTIS [18], MOSOCO [19], CaptureMyEmotion [20], Mi.L.A. [21], Suara Saya [22] and AutiPECS [23]. All these existing studies and applications are developed by scholars and countries of various backgrounds. Therefore, with all these problems stated and to reduce the impacts on autistic childrens' parents, this research is conducted to develop and evaluate a mobilebased learning system that targets at caregivers so that they can help autistic children receive a proper intervention through the Treatment and Education of Autistic and Communication related handicapped Children (TEACCH). Autistic caregivers will gain more knowledge on the intervention technique, especially to those caregivers who are unable to send their autistic children to an autism centre and also it will indirectly answer "What are the alternative support that could be given to caregivers with autistic children?". 